\title{
Effects of Organizational Motives on Relationship Continuity: The Moderating Role of Corporate Cultural Similarity
}

\author{
Apicha Boonpattarakan \\ School of Business Administration, Bangkok University \\ 119 Rama IV Road, Klongtoey, Bangkok 10110, Thailand \\ Tel: 66-2-350-3500 ext.1640Ｅ-mail: apicha1961@yahoo.com
}

Received: March 5, 2012

Accepted: March 26, 2012 Published: May 1, 2012

doi:10.5539/ibr.v5n5p94

URL: http://dx.doi.org/10.5539/ibr.v5n5p94

\begin{abstract}
This study was aimed to disaggregate the relationship commitment construct into organizational motives component and relationship continuity component and investigate the effects of the motives on relationship continuity. These motives were based on the three-component conceptualization of organizational commitment, which included affective, structural, and normative motives. Constructs associated with affective motives were relationship value and trustworthiness, whereas constructs related to structural motives were switching costs and comparison level of the alternatives. Corporate cultural similarity was proposed to be the key construct associated with normative motives. The results showed that all five constructs associated with the three groups of motives had significant effects on relationship continuity. Trustworthiness was found to have the strongest effect on relationship continuity, followed by relationship value, switching costs, comparison level of the alternatives, and corporate cultural similarity. In addition, corporate cultural similarity was found to moderate the effect of switching costs on relationship continuity.
\end{abstract}

Keywords: Relationship continuity, Organizational motives, Relationship commitment, Corporate cultural similarity

\section{Introduction}

The past two decades has seen a growing interest toward building long-term relationships between manufacturers/service firms and their suppliers/service providers/retailers and the shift in the paradigm of business-to-business relationships, from short-term transaction based relationships to long-term working relationships based on mutual benefits and trust (Cannon, Doney, Mullen, \& Petersen, 2010; Ryu, Park, \& Min, 2007; Sheth \& Sharma, 1997). These long-term working relationships are often referred to in industrial marketing as relationship marketing.

In principle, relationship marketing can be described as relational exchanges in which buyers and sellers form a strong, extensive, and long-term relationship (Kumar, 1999; O'malley \& Tynan, 2008; Powers \& Reagan, 2007; Stern \& El-Ansary, 1992). The relationship is interdependent and analogous to the husband-wife relationship. These extensive relationships are often referred to as value-added partnerships (Rese, 2006; Webster, 1992), in which a close, collaborative relationship is the key to the success of the relationship. The success of the collaborative relationship is heavily based on the relationship commitment of the exchange partners, considered to be a key component driving the success of the relationship. The concept of relationship commitment has extensively been studied and become a major theme of study in the paradigm of business-to-business relationships (e.g., Anderson \& Weitz, 1992; Dwyer, Schurr, \& Oh, 1987; Gounaris, 2005; Leonidou, Palihawadana, Chari, \& Leonidou, 2011; Liu, Su, Li, \& Liu, 2010; Moorman, Zaltman, \& Deshpandé, 1992; Morgan \& Hunt, 1994; Ryu, Lee, \& Lee, 2011; Stanko, Bonner, \& Calantone, 2007).

Past studies in interfirm relationships appear to conceptualize relationship commitment as a global construct including both motives and intention to remain in the relationship in the same construct. Morgan and Hunt (1994) defined and measured commitment in terms of intention to maintain the relationship for a long period of time and the firm's maximum effort to maintain the relationship. Anderson and Weitz (1992) as well as Sanchez-Franco (2009) defined and measured commitment in terms of affection, loyalty, care, intention to maintain the relationship for a long period of time, forgiveness, and dedication. Similarly, Dwyer et al. (1987) defined commitment in terms of loyalty, affection, and satisfaction. Leonidou et al. (2011) defined and measured commitment as loyalty, long 
lasting relationship, effort, and investment in time and resources (i.e., switching costs). Likewise, Moorman et al. (1992) as well as Ryu et al. (2011) defined commitment as desire to continue working with the partner firm in the relationship. The definitions and measures of commitment in the past appear to suggest a weakness of past research to distinguish motives from intention to continue the exchange relationship and to study them as separate constructs. Based on Allen and Meyer's (1990, 1996) as well as Meyer and Allen's (1991) three-component conceptualization of organizational commitment, this study was aimed to disaggregate the motives component from the relationship continuity component and investigate the effects of these motives on relationship continuity. The three groups of motives consist of affective, structural, and normative motives. Relationship value and trustworthiness are proposed to be key constructs associated with affective motives. Switching costs and comparison level of the alternatives are proposed to be key constructs concerning structural motives. Corporate cultural similarity is proposed to be the only key construct related to normative motives.

\section{Literature Review}

\subsection{Relationship Continuity}

The development of relationship stability is an ongoing process desired by both the focal firm and the partner firm. (Claycomb \& Frankwick, 2010). Past research has adopted various terms to refer to relationship continuity. For example, Noordewier, John, and Nevin (1990) as well as Heide and John (1990) used the term expectation of continuity to describe the focal firm's intention to continue the exchange relationship for a long period of time. Cannon, Doney, Mullen, and Petersen (2010), Ganesan (1994), as well as Lusch and Brown (1996) used the term long-term orientation to describe the expectation of relationship continuity. Kumar, Bohling, and Ladda (2003) adopted the term relationship intention to refer to intention to continue the exchange relationship. The concept and measures of expectation of continuity, long-term orientation, and relationship intention described above appear to reflect the concept of relationship continuity, i.e., intention to continue the exchange relationship. In this study, relationship continuity is defined as the focal firm's intent or plan to continue the exchange relationship with its service provider. It is analogous to behavioral intention, a well defined concept in psychology and consumer behavior. Hence, relationship continuity is conceptualized to be the result of various organizational motives.

\subsection{Organizational Motives}

Past research in organizations has identified a three component conceptualization of commitment consisting of affective, continuance, and normative components (Allen \& Meyer, 1990, 1996; Meyer \& Allen, 1991). The three components offer different underlying motives for maintaining a relationship. Hence, they can be considered as three different groups of constructs (Allen \& Meyer, 1990, 1996; Meyer \& Allen, 1991). The affective component of commitment can be defined as "the relative strength of an individual's identification with an involvement in a particular organization. Conceptually, it is characterized by at least three factors: a) a strong belief in and acceptance of the organization's goals and values; b) a willingness to exert considerable effort on behalf of the organization; and c) a strong desire to maintain membership in the organization" (Mowday, Porter, \& Steers, 1982, p.27). In this sense, affective commitment appears to involve the ideas of loyalty, care, effort, desire, dedication, and the like. On the other hand, the continuance component of commitment is viewed as a tendency to continue the exchange relationship because of one of the following two factors: "the magnitude and/or number of investments individuals (or side bets) make and a perceived lack of alternatives" (Allen \& Meyer, 1990, p.4). One partner wishes to continue the relationship because of high switching costs and/or the lack of better alternatives. The continuance component of commitment is synonymous with the concept of behavioral commitment or calculative commitment, in which commitment is derived from a calculation of costs and benefits (Allen \& Meyer, 1990, 1996; Geyskens, Steenkamp, Scheer, \& Kumar, 1996; Liu et al., 2010; Mathieu \& Zajac, 1990; Meyer \& Allen, 1991; Mowday et al., 1982). The third component of commitment is normative commitment. This component of commitment is based on the sense of belonging, that is, obligation to remain in a relationship because it is the right and moral thing to do (Allen \& Meyer, 1990, 1996). Normative commitment, according to Wiener (1982, p.471), is defined as "totality of internalized normative pressures to act in a way which meets organizational goals and interests."

Combining concepts from services marketing, business-to-business marketing, organizational behavior, and psychology literature, this study tries to distinguish organizational motives from intention to continue the exchange relationship and study the effects of these motives on relationship continuity. As a result, relationship commitment in this study is conceptualized as a framework consisting of three groups of organizational motives and relationship continuity. The three groups of motives are based on Allen and Meyer's (1990, 1996) as well as Meyer and Allen's (1991) three-component conceptualization of organizational commitment. They consist of affective, structural, and normative motives. Relationship value and trustworthiness are posited to be key constructs associated with affective motives. Switching costs and comparison level of the alternatives are proposed to be key constructs associated with 
structural motives. Corporate cultural similarity is characterized as the only key construct associated with normative motives.

\subsubsection{Affective Motives}

Drawing from the affective component of organizational commitment, affective motives in this study refer to the emotional connection between the focal firm and the partner firm as a result of the focal firm's evaluation of its partner (Mowday et al., 1982). Work experiences are suggested to be factors associated with affective motives. Analogous to "competence" and "comfort" components associated with work experiences suggested by Allen \& Meyer (1990, 1996) as well as Meyer and Allen (1991), "relationship value" and "trustworthiness" are proposed to be two key motives associated with work experiences affecting the focal firm's intention to continue the exchange relationship. The partnership will be maintained if the focal firm is convinced that it has received good value from its partner and feels that its partner has exhibited a trustworthy behavior.

- Relationship Value

Customer value can be conceptualized as "the difference between total customer value and total customer cost. Total customer value is the bundle of benefits customers expect from a given product or service. Total customer cost is the bundle of costs customers expect to incur in evaluating, obtaining, and using the product or service" (Kotler, 1997, p.38). Hence, business-to-business relationship value is similar to the concept of customer value and can be described as the net reward received by the customer/buyer or as a function of price, product quality, service quality, innovation, and image (Fredericks \& Salter II, 1995). Similarly, Zeithaml (1988) suggests that elements of value should include salient intrinsic attributes (i.e., physical composition of the product such as flavor and color in a beverage), extrinsic attributes (i.e., product-related factors that are not part of the physical product such as brand name), perceived quality, other high level abstractions (such as emotional payoff), and sacrifice component which includes both monetary prices and nonmonetary prices (such as time, energy, and effort).

In consumer marketing, perceived product/service value is posited to influence purchase intention or customer loyalty (Chang \& Wildt, 1994; Cronin, Brady, \& Hult, 2000; Fredericks \& Salter II, 1995; Petrick, 2004; Zeithaml, 1988). The higher the value, the higher the degree of customer intention to remain with the same manufacturer or service provider. Applying this conceptualization to an exchange relationship between two firms, the same conclusion may be drawn. When the focal firm believes the products or services offered by its partner firm to be of high value, the focal firm is likely to maintain and continue its working relationship with the partner firm. Relationship value is, therefore, expected to have a positive effect on relationship continuity. This suggests the following hypothesis.

$\mathrm{H}_{1}$ : Relationship value will have a positive effect on relationship continuity.

\section{- Trustworthiness}

Trust and trustworthiness are two separate constructs that have been studied in the past. The definitions of the two have different meanings. Trust occurs when the partner firm is believed by the focal firm in terms of its cooperation and performance. It means that the focal firm believes that the partner firm is credible and responsible (Ben-Ner \& Halldorsson, 2010; Morgan \& Hunt, 1994). Moorman. Deshpandé, and Zaltman (1993) defined trust as a willingness to rely on a partner in whom one has confidence. It is a feeling which is supported by willingness and confidence.

Trustworthiness demonstrates that the partner firm acts a positive and favorable way toward the expectation of the focal firm (Ben-Ner \& Halldorsson, 2010; Colquitt, Scott, \& LePine, 2007). The partner firm has trustworthiness when the focal firm confidently believes that the partner firm is reliable and has high integrity. Hence, trustworthiness is used to describe the partner firm's behavior. Both trust and trustworthiness are important to a business to achieve a successful long-term relationship. They can enhance efficiency, effectiveness, and productivity of business activities.

Trustworthiness is deemed to be the source of competitive advantage for companies. The organizational trustworthiness literature defines trustworthiness as the behavior that supports the expectation that the organization will act in the interests of its employees if its employees exhibit trustworthy behavior (Hodson, 2004; Huff, 2005). Trustworthiness can be referred to as the degree to which an exchange partner can be relied upon. Trustworthiness can be conceptualized as a unidimensional construct or a multi-dimensional construct. As a unidimensional construct, the concept may include the idea of promise keeping and reliability (Moorman et al., 1993; Rotter, 1980). As a multi-dimensional construct, the concept may include the ideas of promise-keeping, honesty, credibility, sincerity, competence, and reliability (Crosby, Evans, \& Cowles, 1990; Ganesan, 1994; Rempel, Holmes, \& Zanna, 1985; Schurr \& Ozanne, 1985). 
In this research, the concept of trustworthiness is based on a unidimensional construct. It can be defined as the reliability and the integrity of the partner firm to perform its obligations faithfully. Past studies in interfirm relationships showed support for the positive effect of trust on commitment and long-term orientation (Anderson \& Weitz, 1992; Ganesan, 1994; Keh \& Xie, 2009; Morgan \& Hunt, 1994). Drawing from this line of reasoning, it can be posited that when the partner firm exhibits a trustworthy behavior, it is likely that the focal firm will be willing to maintain and continue the exchange relationship with its partner. Hence, the following hypothesis is suggested.

$\mathrm{H}_{2}$ : Trustworthiness will have a positive effect on relationship continuity.

\subsubsection{Structural Motives}

Structural motives are conceptualized as forces that create impediments to the termination of a relationship (Wilson, 1995). Structural motives develop over time as the level of the investments, adaptation, and shared technology grows or as a better alternative cannot be found. The decision to maintain a relationship sometimes depends on a trade-off between costs and benefits. Difficulty in terminating the relationship often arises due to "the magnitude of investments" and/or "the perceived lack of alternatives" (Allen \& Meyer, 1990, 1996; Meyer \& Allen, 1991). The partnership will be difficult to terminate if the focal firm has high levels of termination costs or cannot find a better alternative partner. Analogous with the two factors suggested by Allen and Meyer (1990,1996) as well as Meyer and Allen (1991), "switching costs" and "comparison level of the alternatives" are proposed to be the key motives associated with structural motives. Switching costs are similar to the concept of magnitude of investments, whereas comparison level of the alternatives is similar to the concept of perceived lack of alternatives.

\section{- Switching Costs}

Switching costs refer to idiosyncratic investments which may include both tangible and intangible investments (Anderson \& Weitz, 1992; Heide \& John, 1988, 1992; Jackson, 1985; Whitten \& Wakefield, 2006). Tangible switching costs include investments in dollars, people, assets, and procedures, whereas intangible switching costs include exposures to financial, performance, and personal risks (Jackson, 1985; Jones, Mothersbaugh, \& Beatty, 2002; Whitten \& Wakefield, 2006). Switching costs are also referred to as relationship termination costs (Morgan \& Hunt, 1994) or transaction-specific investments described in the transaction cost analysis framework (Williamson, 1975; Williamson, 1985). The concept of switching costs is synonymous with the idea of magnitude of investments, an element of continuance commitment, proposed by Mathieu and Zajac (1990) and Meyer and Allen (1991). These investments are not redeployable and have no value outside the focal relationship. The investments will have to be foregone if the focal firm desires to seek a new partner. Switching costs in this study are defined as the focal firm's investments including tangible and intangible assets that make it difficult for the focal firm to terminate its working relationship with its partner.

To make the relationship a successful one, the focal firm often has to make a lot of investments (mostly intangible investments), such as educating their partner firms about their businesses and spending time working closely with them. High switching costs are therefore likely to bring the two sides closer to each other, lead to a high quality outcome, and make the ongoing relationship being viewed as important, thus generating an intention to continue the exchange relationship. A more durable and lasting relationship is often the result of high switching costs (Joskow, 1987). This parallels Dwyer et al.'s (1987) conceptualization, which suggests that high switching costs give rise to a desire to maintain a relationship. Empirical research also showed a positive effect of switching costs on expectation of continuity (Heide \& John, 1990). High levels of switching costs are expected to act as an impediment to terminate the relationship (Morgan \& Hunt, 1994). The higher the switching costs, the more likely the focal firm's intention to continue the exchange relationship. The following hypothesis is suggested.

$\mathrm{H}_{3}$ : Switching costs will have a positive effect on relationship continuity.

\section{- Comparison Level of the Alternatives}

The concept of comparison level of the alternatives is identical to the idea of perceived lack of alternatives described by Allen and Meyer $(1990,1996)$ and Meyer and Allen (1991). Comparison level of the alternatives can be defined informally as "the lowest level of outcomes a member will accept in the light of available alternative opportunities in other relationships" (Kelley \& Thibaut, 1978, p.9). This definition parallels what Anderson and Narus (1990, p.44) describe as "a standard that represents the overall quality of outcomes (economic, social, and technical) available to the firm from the best alternative exchange relationship." In this research, comparison level of the alternatives is defined as the quality of the outcome of other alternative service providers readily available to the focal firm.

Kelley and Thibaut (1978) and Wilson (1995) provide an explanation of the relationship between comparison level of the alternatives and dependence. The level of outcome received from the current partner when evaluated against the quality of the most attractive of other alternatives is a measure of dependence. If the outcome drops below 
comparison level of the alternatives, the focal firm will discontinue the relationship. If the outcome greatly exceeds comparison level of the alternatives, the focal firm will become more dependent on the relationship (Powers \& Reagan, 2007). Hence, it follows that if the level of comparison level of the alternatives is low, the focal firm will be more likely to continue the relationship because the alternative partners are not very attractive. If the level of comparison level of the alternatives is high, the focal firm will be more likely to discontinue the relationship because the alternative partners are very attractive. Thus, the following hypothesis is proposed.

$\mathrm{H}_{4}$ : Comparison level of the alternatives will have a negative effect on relationship continuity.

\subsubsection{Normative Motives}

Normative motives, the third group of organizational motives, refer to as internalized normative pressures to maintain or terminate the exchange relationship. In this study, "corporate cultural similarity" between the focal firm and the partner firm is considered to be the key normative motive driving the sustainability of the relationship. The concept of corporate culture has been defined as the values and norms shared by employees of an organization. The way the organization behaves and performs will be significantly driven by these values and norms. Past research shows that corporate culture has an effect on organizational performance (Kotter \& Heskett, 1992; Siehl \& Martin, 1990). Relationships will become more sustainable with increased similarity in corporate values and norms (Bucklin \& Sengupta, 1993). Thus, similarity of corporate cultural values and norms between the focal firm and the partner firm will provide a foundation for the development of long-term relationships.

When corporate cultural similarity exists between the exchange partners, the exchange partners will be more likely to communicate closely with each other and have a better understanding of each other's goals and objectives (Zenger \& Lawrence, 1989). In this situation, the exchange partners will focus on the well-being of both sides and be more likely to work closely together as a team (Doney \& Cannon, 1997; Lee, Lee, \& Suh, 2007). Hence, intention to continue the exchange relationship will be high when the corporate cultural similarity between the exchange partners is high. This suggests the following hypothesis.

$\mathrm{H}_{5}$ : Corporate cultural similarity will have a positive effect on relationship continuity.

Corporate cultural similarity has been studied in the past as a moderator in some other contexts (Cannon et al., 2010; Lee et al., 2007). In this study, corporate cultural similarity is proposed to moderate the effects of both affective motives and structural motives on relationship continuity. The influence of affective motives on relationship continuity is expected to be different between the exchange partners with high levels of corporate cultural similarity and those with low levels of corporate cultural similarity. For the exchange partners with high levels of corporate cultural similarity, the affective motives will have a weaker influence on intention to continue the exchange relationship. Because of the high level of corporate cultural similarity, the focal firm and the partner firm will have a better understanding of each other's goals and will work closely with each other and work more effectively to achieve the desired outcomes. The focal firm will be more tolerant and more sympathetic toward the partner firm. As a result, the focal firm will be more likely to maintain the relationship with the partner firm even if the affective motives are not as high as it would like to be. In contrast, for the exchange partners with low levels of corporate cultural similarity, the affective motives will have a stronger influence on intention to continue the exchange relationship. With the difference in corporate culture between the focal firm and the partner firm, the focal firm will only continue the exchange relationship if its affective motives are of high levels. The partner firm will have to exhibit a high level of relationship value and trustworthiness if it would like the focal firm to be satisfied and continue to use its services. This suggests the following hypotheses.

$\mathrm{H}_{6}$ : Relationship value will influence relationship continuity to a greater degree for firms with low corporate cultural similarity than for firms with high corporate cultural similarity.

$\mathrm{H}_{7}$ : Trustworthiness will influence relationship continuity to a greater degree for firms with low corporate cultural similarity than for firms with high corporate cultural similarity.

Similarly, the structural motives will also have a weaker influence on intention to continue the exchange relationship for the exchange partners with high levels of corporate cultural similarity. With a high level of corporate cultural similarity between the focal firm and the partner firm, the two parties will share the same set of values and norms and, as a result, have a good understanding of each other in terms of doing business. The focal firm will be more tolerant with its partner and will try to help its partner to produce better desired results. Hence, the focal firm will be more likely to continue the exchange relationship with its partner firm even though switching costs, one form of structural motives, are somewhat low and good alternative sources of supply, another form of structural motives, are not difficult to locate. The focal firm will be more sympathetic with its partner and try to help its partner as much as it can. In contrast, for the exchange partners with low levels of corporate cultural similarity, the structural motives 
will have a stronger influence on intention to maintain the exchange relationship. When the corporate cultures between the two parties are not similar, work will be strongly based on the results. If the results are not good, switching costs will have a strong effect on relationship continuity. The focal firm will be more likely to form a new strategic alliance with a new partner who can produce better and more valuable results. Likewise, when the partner firm's performance is below what is expected, the focal firm will try to locate a new partner if good alternative sources of supply are readily available in the industry. This leads to the following hypotheses.

$\mathrm{H}_{8}$ : Switching costs will influence relationship continuity to a greater degree for firms with low corporate cultural similarity than for firms with high corporate cultural similarity.

$\mathrm{H}_{9}$ : Comparison level of the alternatives will influence relationship continuity to a greater degree for firms with low corporate cultural similarity than for firms with high corporate cultural similarity.

The development of the proposed conceptual framework and the hypotheses described above is presented in Figure1.

\section{Research Methodology}

A mail survey was used to test the proposed model in the advertising agency industry, a service provider business. Although mail surveys are likely to generate low response rates, they are a common method used in studying relational exchanges. The mail survey appears to be appropriate for this type of research because it can effectively reach busy business executives in organizations that are scattered throughout the geographic area at relatively low cost. Other advantages of mail surveys include an opportunity to have a large sample, allow researchers to obtain a large amount of information, and give respondents confidentiality in answering (Erdos \& Morgan, 1983).

This study focuses on the buyer side, i.e., the advertisers. The emphasis is on the perception of advertisers regarding their ad agency relationships. As a result, the population of interest in this study is defined as advertisers who use the service of an outside advertising agency. The sampling frame was constructed from the listing of advertisers in the most recent U.S. standard directory of advertisers. Population members were identified and included in the sampling frame when the listing indicated that the advertiser organization used the service of an outside advertising agency. A simple random sampling was used to select the total number of 2,000 advertisers from the sampling frame.

The first draft of the questionnaire was constructed by adapting previous measures published in the literature. All constructs were measured using multiple items except corporate cultural similarity (Churchill, 1979). Then, the questionnaire was submitted to a panel of five academic experts for evaluation and suggestions. They were asked to analyze problems with question wording, inadequate or confusing response categories, and any other aspects of the questionnaire perceived to be inadequate or irrelevant. The recommendations were used to modify the questionnaire.

Next, a formal pretest was carried out. A random sample of 100 advertisers who used an outside ad agency was used for the study. A questionnaire packet was sent to each advertiser firm's director of advertising, director of marketing communications, or director of marketing. After two weeks of the initial mailing, a follow-up with a reminder letter and a new copy of the questionnaire was sent to nonrespondents. The total of eighteen completed responses was received. Alpha coefficients were computed for constructs with multiple items. Comparison level of the alternatives appeared to have a low reliability index. Changes in wording were then made to the measures of comparison level of the alternatives. The final version of the questionnaire was then used to do the data collection to test the model proposed in this study. The final measures of each construct are presented in Table 1.

The key informant technique was used to collect data (Seidler, 1974). The listing of job titles was used to identify key informants. Each sample unit was then sent a questionnaire packet. The recipient was asked to select and focus on one primary ad agency if multiple ad agencies were used. Then, the recipient was asked to complete the questionnaire if he or she was qualified or forward the questionnaire to a qualified person in the organization. To stimulate response cooperation, incentives were provided to recipients (Dillman, 1978). A copy of the summary of the findings was offered to recipients. Questionnaire recipients were also assured of confidentiality. There were informed that no individual identity would be revealed; only the aggregate results would be presented. First, the entire sample of 2,000 was mailed a questionnaire packet requesting their participation. Then, three weeks after the initial mailing, nonrespondents were sent a reminder letter and a new copy of the questionnaire.

\section{Analysis and Results}

Of the original sample size of 2,000, 86 were undeliverable. Hence, the number of deliverable questionnaires was 1,914. The total number of completed questionnaires received was 357 . This represented an $18.65 \%$ response rate. A comparison was made between early and late responses. A two sample t-test was conducted to test the differences between early and late responses in terms of the advertiser's revenues, length of the relationship between the advertiser and the ad agency, and the length of the relationship between the informant and the ad agency. The results 
showed no differences between early and late responses $(\mathrm{p}>0.10)$. Hence, nonresponse bias was not an issue in this research.

\subsection{Sample Characteristics}

Descriptive statistics regarding the sample characteristics were computed. The mean number of employees was 3,677 with a standard deviation of 10,418 and the range was from 4 to 95,000 . The mean revenue reported was $\$ 1,134.93$ million with a standard deviation of $\$ 3,079.31$ million and the range was from $\$ 1.2$ million to $\$ 35,000$ million. In terms of business classification, thirty four percent of advertisers reported being in a consumer product category, $37.1 \%$ in an industrial product category, $26.3 \%$ in a service category, and $2.6 \%$ in other business categories. Creation of advertising, media planning and placement, and strategic advertising planning were reported as the primary purposes for employing the services of ad agencies.

\subsection{Data Analysis and Hypothesis Testing}

Before proceeding with statistical analyses, missing values for each scale item were substituted with the scale item's mean (Cohen \& Cohen, 1983). Methods suggested by Churchill (1979) were then used to purify the measures. Factor analysis using promax rotation was used to check the unidimensionality of constructs with multiple items (Gorsuch, 1983). The purpose was to check the unidimensionality of each construct, not to identify the underlying factors or constructs. Hence, we checked those constructs with multiple items one by one. The results suggested the unidimensionality of all the constructs using multiple items.

The next step was to compute coefficient alphas for constructs with multiple items. Only item number four of the switching costs construct exhibited a very low correlation with total. Hence, this item was dropped from further analyses. The final coefficient alphas were 0.916 for relationship value, 0.813 for trustworthiness, 0.743 for switching costs, 0.625 for comparison level of the alternatives, and 0.887 for relationship continuity. These coefficient alphas were considered acceptable (Churchill \& Peter, 1984; Nunnally, 1967).

LISREL 8.53 was used to analyze convergent validity through the use of confirmatory factor analysis. All the constructs with multiple items were treated as exogenous variables and allowed to covary. Correlation matrix was used as an input. The results showed that all the lambdas of indicators were highly significant. All $t$-values were well above $1.96(\mathrm{p}<0.05)$. As a result, all constructs with multiple items appeared to have convergence in measurement (Bagozzi \& Yi, 1988). The composite reliabilities of individual constructs were then computed. All indexes were acceptable. They were all above 0.6 (Bagozzi \& Yi, 1988). The computed composite reliability were 0.921 for relationship value, 0.836 for trustworthiness, 0.757 for switching costs, 0.613 for comparison level of the alternatives, and 0.893 for relationship continuity.

Then, a 95\% confidence interval of the correlation for each pair of constructs was computed. The computation was based on plus or minus 1.96 standard errors around each correlation. The lower bound and the upper bound were then obtained. The results showed that none of the confidence intervals included or were very close to 1.0. This suggested the presence of discriminant validity among constructs using multiple items (Anderson, 1987).

An OLS regression analysis was used to test the hypotheses. The regression analysis results are reported in Table 2 . The model had an R-square of 0.780 . The findings showed that relationship value, trustworthiness, switching costs, and comparison level of alternatives had significant effects on relationship continuity $(p<0.001)$. Corporate cultural similarity was also found to have a significant effect on relationship continuity $(\mathrm{p}<0.05)$. In addition, corporate cultural similarity was found to only moderate the effect of switching costs on relationship continuity $(\mathrm{p}<0.05)$. Corporate cultural similarity did not significantly moderate the effects of relationship value, trustworthiness, and comparison level of alternatives on relationship continuity ( $p>0.05$ ). It can be concluded that $\mathrm{H}_{1}, \mathrm{H}_{2}, \mathrm{H}_{3}, \mathrm{H}_{4}, \mathrm{H}_{5}$, and $\mathrm{H}_{8}$ are statistically supported, while $\mathrm{H}_{6}, \mathrm{H}_{7}$, and $\mathrm{H}_{9}$ are not statistically supported.

\section{Discussion}

The proposed model suggests that organizational motives associated with affection, structure, and culture/norms should influence the focal firm's intention to maintain the exchange relationship. The results showed that all constructs associated affective, structural, and normative motives were found to have an influential effect on the focal firm's intention to maintain and continue using the partner firm, a business service provider. Hence, all the hypothesized main effects in the model were supported. The findings indicate that the two types of motives associated with affection have significant effects on relationship continuity. The study shows that relationship value is an influential factor affecting customer loyalty, i.e., the focal firm's intention to continue working with the partner firm. In a service providing industry in which the focal firm is not heavily dependent on the partner firm (i.e., service providing firm) and the availability of alternative service providers is not a major issue, value is likely to be a very important factor in determining the continuity of the relationship. If the service provider is unable to render 
high value, then the focal firm is likely to search for an alternative service provider. Likewise, the partner firm's trustworthiness is also a key factor in determining relationship continuity. The research shows that trustworthiness is a key component in maintaining a long-term relationship. The relationship cannot be sustained if the partner firm's trustworthiness diminishes. If the focal firm does not believe that the partner firm will do whatever it can to protect the focal firm's interests, the focal firm will stop using the service of the partner firm. Therefore, the partner firm's trustworthiness is considered to be an influential component affecting relationship continuity.

Similarly, the two motives associated with structure were also found to impact the focal firm's intention to continue the exchange relationship. Switching costs have a positive impact on the focal firm's intention to continue the exchange relationship. The higher the switching costs, the higher the level of relationship continuity. In a service providing industry, switching costs are mostly in the form of time. The focal firm has to spend a great deal of time working with the service providing firm. The service provider is often considered part of the focal firm. Seeking a new service provider often takes time and effort. As a result, switching costs are likely to have an effect on the focal firm's decision whether or not to continue working with the service provider. As expected, the comparison level of the alternatives was found to have a significant effect on relationship continuity. The lower the comparison level of the alternatives, the higher the focal firm's intention to continue working with the current service providing firm. This means that the service providing firm's reputation is a key determinant of relationship continuity. The relationship will continue if the focal firm is confident that the partner firm it has been working with is reputed to be one of the best service providers in the industry.

In addition, corporate cultural similarity between the focal firm and the partner firm also has an influential effect on relationship continuity. Similarity in corporate culture will help strengthen the working relationship. With similar values and norms, the focal firm and the partner firm will be able to communicate with each other more effectively and more efficiently to produce the desired results. This suggests that in selecting a service providing firm, the focal firm must try to select a service provider with similar values and norms since similarity in corporate values and norms is a key component driving the success and sustainability of the relationship.

When examining the standardized coefficients (see Table 2) of all the five significant motives influencing intention to continue the exchange relationship, trustworthiness appears to have the strongest effect on relationship continuity, followed by relationship value, switching costs, comparison level of the alternatives, and corporate cultural similarity. The two most important motives in remaining in the exchange relationship are trustworthiness and relationship value. Of these two motives, trustworthiness has a slightly stronger effect than relationship value. The relationship will never work if trustworthiness and relationship value are perceived to be low. Thus, as a business service provider, we must concentrate on building trustworthiness and providing excellent service value to the focal firm if we would like to build a long-term relationship with the focal firm. Of the two motives associated with structure, switching costs have a stronger effect than comparison level of the alternatives. Spending time and working closely with the focal firm will help strengthen the relationship since the major form of switching costs in the business service industry is time. In addition, the focal firm will be most likely to continue working with the same service provider if it perceives its service provider to be one of the best service providers in the industry. Hence, one important priority the partner firm should do is to build its reputation by providing good service values to all of its customers. Rendering good service values is therefore a key determinant of the partner firm's reputation.

Regarding the four hypothesized moderating effects, only one was found to be statistically significant. Corporate cultural similarity was found to moderate the effect of switching costs on relationship continuity. With a high level of corporate cultural similarity, the focal firm and the partner will have a better understanding of each other and the focal firm will be more tolerant and more sympathetic with its service provider. The focal firm will be more likely to stay in the relationship even though the switching costs are somewhat low and not considered an obstacle for leaving the current relationship. In contrast, when the corporate cultural similarity is low, the effect of switching costs on relationship continuity will be stronger. If the switching costs are not high enough and the work results are below the acceptable level, the focal firm will be more likely to consider leaving the relationship. Hence, in choosing a partner, a business service provider must consider choosing the partner who has similar corporate cultural values and norms. Figure 2 shows the results of the moderating effects of corporate cultural similarity on the effects of switching costs on relationship continuity.

\section{Contribution and Managerial Implications}

The primary contribution of this study is the conceptualization of the structure of relationship commitment. The study attempts to disaggregate the commitment construct into components consisting of motives and relationship continuity. In the past, commitment construct was perceived to be a global construct combining motives and relationship continuity in the same construct and, hence creating a confounding effect among motives, commitment 
construct, and relationship outcomes. Relationship commitment, theorized in the past to be a key mediating variable, was perceived to be a redundant variable and, thus, was not included in the proposed model. This study theorizes that relationship value, trustworthiness, switching costs, and comparison level of the alternatives, and corporate cultural similarity are key organizational motives affecting relationship continuity.

The success of interfirm relationship is dependent on both the focal firm and the partner firm. Both sides need to fully understand each other and must be seriously involved in building the relationship. The two key affective motives in building long-term relationships are relationship value and trustworthiness. This means that a long-term relationship will significantly depend on the value of work provided by the partner firm and the level of the partner firm's trustworthiness perceived by the focal firm. There are several means the partner firm could do to improve its value perceived by the focal firm. The partner needs to make sure that all personnel involved in the service thoroughly understand the focal firm's business since understanding the focal firm's business will lead to producing work that corresponds to the need of the focal firm. Relationship value will increase if the partner firm can show that it has put a great deal of effort in working for the focal firm. Constantly being in contact with the focal firm will also help demonstrate the partner firm's effort. To create a high level of trustworthiness, the partner firm may have to show that it provides timely and accurate information concerning the focal firm's business, keep the focal firm informed of its work, and do not withhold any information.

Understanding the effects of structural motives will also help the partner firm achieve its goals. The partner firm may try to increase the focal firm's switching costs by involving the focal firm in the work process and work closely with the focal firm. Once the focal firm has become involved, its switching costs will go up and, as a result, it will probably become more patient with the ongoing relationship. In addition, the partner firm must demonstrate that it is one of the best alternatives available in the industry. Employing high quality personnel may help the partner firm accomplish this goal. As for both the focal firm and the partner firm, one implication is that when selecting a partner one should try to select the partner that has similar shared values and norms. Relationships will not be durable if there is a clash in corporate culture. Similarity in corporate culture is expected to lead to a better working relationship between the focal firm and the partner firm.

\section{Limitations and Future Research}

The proposed model focuses on the exchange relationships in a business service industry. We need to extend the research by testing the model with other types of exchange relationships, such as the exchange relationships between manufacturing companies and their suppliers (in terms of materials, parts, or components) and between manufacturing companies and their retailers. The strengths of the effects of various motives in other types of relationships may be different from the effects found in this study. Another area for future research is to adapt the model to consumer marketing and study the relationship between service providers and end users, such as between mobile phone service providers or credit card service providers and their customers. In this type of relationship, some of the constructs in the model may not be applicable. These constructs may have to be replaced with other similar constructs. For example, instead of having corporate cultural similarity as a construct associated with normative motives, a construct related to the influence of family members or friends (i.e., a sense of belonging to a group) may be used. Likewise, satisfaction construct may be included in the model as part of relationship outcomes. Another area of research is to study the antecedents of organizational motives. For example, perceived quality and price may be proposed to be antecedents of relationship value. Constructs, such as interpersonal chemistry and communication openness may be proposed to be antecedents of trustworthiness. In addition, researchers may also want to examine the antecedents of switching costs, comparison level of the alternatives, and corporate cultural similarity.

\section{Conclusion}

The major contribution of this study is the conceptualization of relationship commitment structure. The study examined relationship commitment construct and disaggregated it into components consisting of organizational motives and relationship continuity. The focus was on the effects of these organizational motives on relationship continuity. Based on those concepts developed in organizational research, the three groups of organizational motives were adopted in this study. They consisted of affective motives, structural motives, and normative motives. Relationship value and trustworthiness were proposed to be associated with affective motives. Switching costs and comparison level of the alternatives were proposed to be associated with structural motives. Corporate cultural similarity was proposed to be associated with normative motives. The results of the study suggest that all constructs associated with the three groups of organizational motives influence relationship continuity. In addition, corporate cultural similarity was also found to moderate the effect of switching costs on relationship continuity. Hence, in 
developing a long-term relationship, one must seriously take into account the effects of relationship value, trustworthiness, switching costs, comparison level of the alternatives, and corporate cultural similarity.

\section{References}

Allen, N. J., \& Meyer, J. P. (1990). The measurement and antecedents of affective, continuance, and normative commitment to the organization. Journal of Occupational Psychology, 63(1), 1-18. http://dx.doi.org/10.1111/j.2044-8325.1990.tb00506.x

Allen, N. J., \& Meyer, J. P. (1996). Affective, Continuance, and Normative Commitment to the Organization: An Examination of Construct Validity. Journal of Vocational Behavior, 49(3), 252-276. http://dx.doi.org/10.1006/jvbe.1996.0043

Anderson, E., \& Weitz, B. (1992). The use of pledges to build and sustain commitment in distribution channels. Journal Marketing Research, 29(1), 18-34. http://dx.doi.org/10.2307/3172490

Anderson, J. C. (1987). An approach for confirmatory measurement and structural equation modeling of organizational properties. Management Science, 33(4), 525-541. http://dx.doi.org/10.1287/mnsc.33.4.525

Anderson, J. C., \& Narus, J. A. (1990). A model of distributor firm and manufacturer firm working partnerships. Journal of Marketing, 54(1), 42-58. http://dx.doi.org/10.2307/1252172

Bagozzi, R. P., \& Yi, Y. (1988). On the evaluation of structural equation models. Journal of the Academy of Marketing Science, 16(1), 74-94. http://dx.doi.org/10.1007/BF02723327

Ben-Ner, A., \& Halldorsson, F. (2010). Trusting and trustworthiness: What are they, how to measure them, and what affects them. Journal of Economic Psychology, 31(1), 64-79. http://dx.doi.org/10.1016/j.joep.2009.10.001

Bolton, R. N., \& Drew, J. H. (1991). A multistage model of customers assessments of service quality and value. Journal of Consumer Research, 17(4), 375-384. http://dx.doi.org/10.1086/208564

Bucklin, L. P., \& Sengupta, S. (1993). Organizing successful co-marketing alliances. Journal of Marketing, 57(4), 32-46. http://dx.doi.org/10.2307/1252025

Cannon, J. P., Doney, P. M., Mullen, M. R., \& Petersen, K. J. (2010). Building long-term orientation in buyer-supplier relationships: The moderating role of culture. Journal of Operations Management, 28(6), 506-521. http://dx.doi.org/10.1016/j.jom.2010.02.002

Chang, T-Z., \& Wildt, A. R. (1994). Price, product information, and purchase intention: An empirical study. Journal of the Academy of Marketing Science, 22(1), 16-27. http://dx.doi.org/10.1177/0092070394221002

Churchill, G. A. Jr. (1979). A paradigm for developing better measures of marketing constructs. Journal of Marketing Research, 16(1), 64-73. http://dx.doi.org/10.2307/3150876

Churchill, G. A., Jr., \& Peter, J. P. (1984). Research design effects on the reliability of rating scales: A meta-analysis. Journal of Marketing Research, 21(4), 360-375. http://dx.doi.org/10.2307/3151463

Claycomb, C., \& Frankwick, G. L. (2010). Buyers' perspectives of buyer-seller relationship development. Industrial Marketing Management, 39(2), 252-263. http://dx.doi.org/10.1016/j.indmarman.2008.08.004

Cohen, J., \& Cohen, P. (1983). Applied multiple regression/correlation analysis for the behavioral sciences. Hillsdale, NJ: Lawrence Erlbaum Associates.

Colquitt, J. A., Scott, B. A., \& LePine, J. A. (2007). Trust, trustworthiness, and trust propensity: A meta-analytic test of their unique relationships with risk taking and job performance. Journal of Applied Psychology, 92(4), 909-927. http://dx.doi.org/10.1037/0021-9010.92.4.909

Cronin, J. J., Brady, M. K., \& Hult, G. T. M. (2000). Assessing the effects of quality, value and customer satisfaction on consumer behavioral intentions in service environments. Journal of Retailing, 76(2), 193-218. http://dx.doi.org/10.1016/S0022-4359(00)00028-2

Crosby, L. A., Evans, K. R., \& Cowles, D. (1990). Relationship quality in services selling: An interpersonal influence perspective. Journal of Marketing, 54(3), 68-81. http://dx.doi.org/10.2307/1251817

Deshpandé, R., \& Webster, F. E., Jr. (1989). Organizational culture and marketing: Defining the research agenda. Journal of Marketing, 53(1), 3-15. http://dx.doi.org/10.2307/1251521

Dillman, D. A. (1978). Mail and telephone surveys: The total design method. New York: John Wiley \& Sons.

Doney, P. M., \& Cannon, J. P. (1997). An examination of the nature of trust in buyer-seller relationships. Journal of Marketing, 61(2), 35-51. http://dx.doi.org/10.2307/1251829 
Dwyer, F. R., Schurr, P. H., \& Oh, S. (1987). Developing buyer-seller relationships. Journal of Marketing, 51(2), 11-27. http://dx.doi.org/10.2307/1251126

Erdos, P. L., \& Morgan, A. J. (1983). Professional mail surveys. Malabar, FL: Robert E. Krieger Publishing Company.

Fredericks, J. O., \& Salter, J. M. II. (1995). Beyond customer satisfaction. Management Review, 84(5), 29-32.

Ganesan, S. (1994). Determinants of long-term orientation in buyer-seller relationships. Journal of Marketing, 58(2), 1-19. http://dx.doi.org/10.2307/1252265

Geyskens, I., Steenkamp, J-B. E. M., Scheer, L. K., \& Kumar, N. (1996). The effects of trust and interdependence on relationship commitment: A trans-atlantic study. International Journal of Research in Marketing, 13(4), 303-317. http://dx.doi.org/10.1016/S0167-8116(96)00006-7

Gorsuch, R. L. (1983). Factor analysis. Hillsdale, NJ: Lawrence Erlbaum Associates, Inc.

Gounaris, S. P. (2005). Trust and commitment influences on customer retention: Insights from business-to-business services. Journal of Business Research, 58, 126-140. http://dx.doi.org/10.1016/S0148-2963(03)00122-X

Han, S-L. (1992). Antecedents of buyer-seller long-term relationships: An exploratory model of structural bonding and social bonding. (Unpublished Paper). ISBM Report 6-1992, Penn State University.

Heide, J. B., \& John, G. (1988). The role of dependence balancing in safeguarding transaction-specific assets in conventional channels. Journal of Marketing, 52(1), 20-35. http://dx.doi.org/10.2307/1251683

Heide, J. B., \& John, G. (1990). Alliances in industrial purchasing: The determinants of joint action in buyer-supplier relationships. Journal of Marketing Research, 27(1), 24-36. http://dx.doi.org/10.2307/3172548

Heide, J. B., \& John, G. (1992). Do norms matter in marketing relationships?. Journal of Marketing, 56(2), 32-44. http://dx.doi.org/10.2307/1252040

Hodson, R. (2004). Organizational trustworthiness: Findings from the population of organizational ethnographies. Organization Science, 15(4), 432-445. http://dx.doi.org/10.1287/orsc.1040.0077

Huff, L. C. (2005). Stages in the development of customers' trust for services providers. Asia Pacific Advances in Consumer Research, 6, 105-10.

Jackson, B. B. (1985). Winning and keeping industrial customers: The dynamics of customer relationships. Lexington, KY: Lexington Books.

Jones, M. A., Mothersbaugh, D. L., \& Beatty, S. E. (2002). Why customers stay: Measuring the underlying dimensions of services switching costs and managing their differential strategic outcomes. Journal of Business Research, 55(6), 441-450. http://dx.doi.org/10.1016/S0148-2963(00)00168-5

Joskow, P. L. (1987). Contract duration and relationship-specific investments: Empirical evidence from coal markets. American Economic Review, 77(1), 168-185.

Keh, H. T., \& Xie, Y. (2009). Corporate reputation and customer behavioral intentions: The roles of trust, identification and commitment. Industrial Marketing Management, 38(7), 732-742. http://dx.doi.org/10.1016/j.indmarman.2008.02.005

Kelley, H. H., \& Thibaut, J. W. (1978). Interpersonal relations: A theory of interdependence. New York: John Wiley \& Sons, Inc.

Kotler, P. (1997). Marketing management: Analysis, planning, implementation, and control (9th ed.). Upper Saddle River, NJ: Prentice Hall.

Kotter, J. P., \& Heskett, J. L. (1992). Corporate culture and performance. New York: The Free Press.

Kumar, P. (1999). The impact of long-term client relationships on the performance of business service firms. Journal of Service Research, 2(1), 4-18. http://dx.doi.org/10.1177/109467059921002

Kumar, V., Bohling, T. R., \& Ladda, R. N. (2003). Antecedents and consequences of relationship intention: Implications for transaction and relationship marketing. Industrial Marketing Management, 32(8), 667-676. http://dx.doi.org/10.1016/j.indmarman.2003.06.007

Lee, D. J., Lee, M., \& Suh, J. (2007). Benevolence in the importer-exporter relationship: Moderating role of value similarity and cultural familiarity. International Marketing Review, 24(6), 657-677. http://dx.doi.org/10.1108/02651330710832649 
Leonidou, L. C., Palihawadana, D., Chari, S., \& Leonidou, C. N. (2011). Drivers and outcomes of importer adaptation in international buyer-seller relationships. Journal of World Business, 46(4), 527-543. http://dx.doi.org/10.1016/j.jwb.2010.10.013

Liu, Y., Su, C., Li, Y., \& Liu, T. (2010). Managing opportunism in a developing interfirm relationship: The interrelationship of calculative and loyalty commitment. Industrial Marketing Management, 39(5), 844-852. http://dx.doi.org/10.1016/j.indmarman.2009.09.004

Lusch, R. F., \& Brown, J. R. (1996). Interdependency, contracting, and relational behavior in marketing channels. Journal of Marketing, 60(4), 19-38. http://dx.doi.org/10.2307/1251899

Mathieu, J. E., \& Zajac, D. M. (1990). A review and meta-analysis of the antecedents, correlates, and consequences of organizational commitment. Psychological Bulletin, 108(2), 171-194. http://dx.doi.org/10.1037/0033-2909.108.2.171

Meyer, J. P., \& Allen, N. J. (1991). A three-component conceptualization of organizational commitment. Human Resource Management Review, 1(1), 61-89. http://dx.doi.org/10.1016/1053-4822(91)90011-Z

Moorman, C., Deshpandé, R., \& Zaltman, G. (1993). Factors affecting trust in market research relationships. Journal of Marketing, 57(1), 81-101. http://dx.doi.org/10.2307/1252059

Moorman, C., Zaltman, G., \& Deshpandé, R. (1992). Relationships between providers and uses of marketing research: The dynamics of trust within and between organizations. Journal of Marketing Research, 29(3), 314-329. http://dx.doi.org/10.2307/3172742

Morgan, R. M., \& Hunt, S. D. (1994). The commitment-trust theory of relationship marketing. Journal of Marketing, 58(3), 20-38. http://dx.doi.org/10.2307/1252308

Mowday, R. T., Porter, L. W., \& Steers, R. M. (1982). Employee-organizational linkages. New York: Academic Press.

Noordewier, T. G., John, G., \& Nevin, J. R. (1990). Performance outcomes of purchasing arrangements in industrial buyer-vendor relationships. Journal of Marketing, 54(4), 80-93. http://dx.doi.org/10.2307/1251761

Nunnally, J. C. (1967). Psychometric theory. New York: McGraw Hill.

O’malley, L., \& Tynan, C. (2008). Relationship marketing. In M. J. Baker \& S. Hart (Eds.), The marketing book (pp. 33-54). Burlington, MA: Butterworth-Heinemann.

Petrick, J. F. (2004). The roles of quality, value and satisfaction in predicting cruise passengers' behavioral intentions. Journal of Travel Research, 42(4), 397-407. http://dx.doi.org/10.1177/0047287504263037

Powers, T. L., \& Reagan, W. R. (2007). Factors influencing successful buyer-seller relationships. Journal of Business Research, 60(12), 1234-1242. http://dx.doi.org/10.1016/j.jbusres.2007.04.008

Rempel, J. K., Holmes, J. G., \& Zanna, M. P. (1985). Trust in close relationships. Journal of Personality and Social Psychology, 49(1), 95-112. http://dx.doi.org/10.1037/0022-3514.49.1.95

Rese, M. (2006). Successful and sustainable business partnerships: How to select the right partners. Industrial Marketing Management, 35(1), 72-82. http://dx.doi.org/10.1016/j.indmarman.2005.08.009

Rotter, J. B. (1980). Interpersonal trust, trustworthiness, and gullibility. American Psychologist, 35(1), 17. http://dx.doi.org/10.1037/0003-066X.35.1.1

Ryu, S., Lee, E-J., \& Lee, W. J. (2011). A cross-cultural study of interfirm power structure and commitment: The effect of collectivism. Journal of Business \& Industrial Marketing, 26(2), 92-103. http://dx.doi.org/10.1108/08858621111112276

Ryu, S., Park, J. E., \& Min, S. (2007). Factors of determining long-term orientation in interfirm relationships. Journal of Business Research, 60(12), 1225-1233. http://dx.doi.org/10.1016/j.jbusres.2006.09.031

Sanchez-Franco, M. J. (2009). The moderating effects of involvement on the relationships between satisfaction, trust and commitment in e-banking. Journal of Interactive Marketing, 23, 247-258. http://dx.doi.org/10.1016/j.intmar.2009.04.007

Schurr, P. H., \& Ozanne, J. L. (1985). Influences on exchange processes: Buyers' preconceptions of a seller's trustworthiness and bargaining toughness. Journal of Consumer Research, 11(4), 939-953. http://dx.doi.org/10.1086/209028 
Seidler, J. (1974). On using informants: A technique for collecting quantitative data and controlling measurement data in organizational analysis. American Sociological Review, 39(6), 816-831. http://dx.doi.org/10.2307/2094155

Sheth, J. N., \& Sharma, A. (1997). Supplier relationships: Emerging issues and challenges. Industrial Marketing Management, 26(2), 91-100. http://dx.doi.org/10.1016/S0019-8501(96)00153-8

Siehl, C., \& Martin, J. (1990). Organizational culture: A key to financial performance? In B. Schneider (Ed.), Organizational climate and culture (pp. 241-281). San Francisco: Jossey-Bass.

Stanko, M. A., Bonner, J. M., \& Calantone, R. J. (2007). Building commitment in buyer-seller relationships: A tie strength perspective. Industrial Marketing Management, 36, 1094-1103. http://dx.doi.org/10.1016/j.indmarman.2006.10.001

Stern, L. W., \& El-Ansary, A. I. (1992). Marketing channels (4th ed.). Englewood Cliffs, NJ: Prentice Hall.

Webster, F. E. Jr. (1992). The changing role of marketing in the corporation. Journal of Marketing, 56(4), 1-17. http://dx.doi.org/10.2307/1251983

Whitten, D., \& Wakefield, R. L. (2006). Measuring switching costs in IT outsourcing services. Journal of Strategic Information Systems, 15(3), 219-248. http://dx.doi.org/10.1016/j.jsis.2005.11.002

Wiener, Y. (1982). Commitment in organizations: A normative view. Academy of Management Review, 7(3), 418-428. http://dx.doi.org/10.2307/257334

Williamson, O. E. (1975). Markets and hierarchies: Analysis and antitrust implications. New York: The Free Press.

Williamson, O. E. (1985). The economic institutions of capitalism: Firms, markets, relational contracting. New York: The Free Press.

Wilson, D. T. (1995). An integrated model of buyer-seller relationships. Journal of the Academy of Marketing Science, 23(4), 335-345. http://dx.doi.org/10.1177/009207039502300414

Zeithaml, V. A. (1988). A consumer perceptions of price, quality, and value: A means-end model and synthesis of evidence. Journal of Marketing, 52(3), 2-22. http://dx.doi.org/10.2307/1251446

Zenger, T. R., \& Lawrence, B. S. (1989). Organizational demography: The differential effects of age and tenure distributions on technical communication. The Academy of Management Journal, 32(2), 353-376. http://dx.doi.org/10.2307/256366 
Table 1. Measurement of constructs

\section{Relationship Value}

3 item--5 point numerical scale--Anchored at endpoints

* Please circle the number in each of the following items that best describes the overall value of services provided by this ad agency, given what it paid for services rendered.

1. Poor/Good

2. Worthless/Worthwhile

3. Valueless/Valuable

Source: Adapted from Bolton and Drew (1991).

\section{Trustworthiness}

6 items--5 point Likert scale--Anchored at endpoints

(Strongly Disagree/Strongly Agree)

1. We believe the information that this ad agency provides us.

2. This ad agency is always honest with us.

3. This ad agency does not always keep promises it makes to us. (R)

4. When making important decisions, this ad agency considers our welfare as well as its own.

5. This ad agency keeps our best interests in mind.

6. Sometimes, we find it necessary to be cautious with this ad agency. (R)

Source: Adapted from Doney and Cannon (1997).

\section{Switching Costs}

5 items--5 point Likert scale--Anchored at endpoints

(Strongly Disagree/Strongly Agree)

1. If we decided to stop working with this ad agency, we would be wasting a lot of knowledge that is tailored to its methods.

2. We have invested a great deal of time in working with this ad agency.

3. If we switched to an alternative ad agency, we would lose much of the investment we have made in the relationship with this ad agency.

4. This ad agency has ways of doing business that have required adaptation on our part.

5. We have made a substantial investment in getting this ad agency to fully understand our business.

Source: Adapted from Anderson and Weitz (1992) as well as from Heide and John (1992).

\section{Comparison Level of the Alternatives}

3 items--5 point Likert scale--Anchored at endpoints

(Strongly Disagree/Strongly Agree)

1. It would be easy for us to find a better alternative ad agency who can provide us with better results.

2. There are other highly attractive alternative ad agencies readily available to us.

3. The ad agency we are currently working with is the best ad agency available to us. (R)

Source: Adapted from Han (1992).

\section{Corporate Cultural similarity}

1 item--5 point Likert scale--Anchored at endpoints

(Strongly Disagree/Strongly Agree)

* The corporate culture of our organization is similar to that of the ad agency.

Source: Adapted from Lee et al. (2007).

\section{Relationship Continuity}

3 items--5 point Likert scale--Anchored at endpoints

(Strongly Disagree/Strongly Agree)

1. We expect our relationship with this ad agency to continue for a long time.

2. Our relationship with this ad agency is enduring.

3. We intend to leave this ad agency in the near future. (R)

Source: Adapted from Lusch and Brown (1996) and from Noordewier et al. (1990). 
Table 2. Effects of affective, structural, and normative motives on relationship continuity

\begin{tabular}{lllll}
\hline Independent Variables & Standardized Beta & t-value & p-value & VIF \\
\hline Relationship Value & 0.310 & 6.572 & $0.000^{* * *}$ & 1.973 \\
Trustworthiness & 0.319 & 6.768 & $0.000^{* * *}$ & 1.968 \\
Switching Costs & 0.171 & 4.715 & $0.000^{* * *}$ & 1.169 \\
Comparison Level of the Alternatives & -0.161 & -4.070 & $0.000^{* * *}$ & 1.392 \\
Corporate Cultural Similarity & 0.073 & 2.020 & $0.044^{*}$ & 1.145 \\
Corporate Cultural Similarity x Relationship Value & -0.035 & -0.690 & 0.491 & 2.254 \\
Corporate Cultural Similarity x Trustworthiness & 0.048 & 0.979 & 0.328 & 2.149 \\
Corporate Cultural Similarity x Switching Costs & -0.080 & -2.104 & $0.036^{*}$ & 1.270 \\
Corporate Cultural Similarity x Comparison Level of the Alternatives & 0.048 & 1.160 & 0.247 & 1.537 \\
\hline
\end{tabular}

Note: Dependent Variable $=$ Relationship Continuity; $\mathrm{R}^{2}=0.780, \mathrm{~F}=59.931$, $\mathrm{p}$-value $=0.000$.

${ }^{* * *}$ Significant at $0.001 ;{ }^{* *}$ Significant at $0.01 ;{ }^{*}$ Significant at 0.05 .

\section{Affective Motives}

\section{- Relationship Value \\ - Trustworth iness}

\section{Structural Motives}

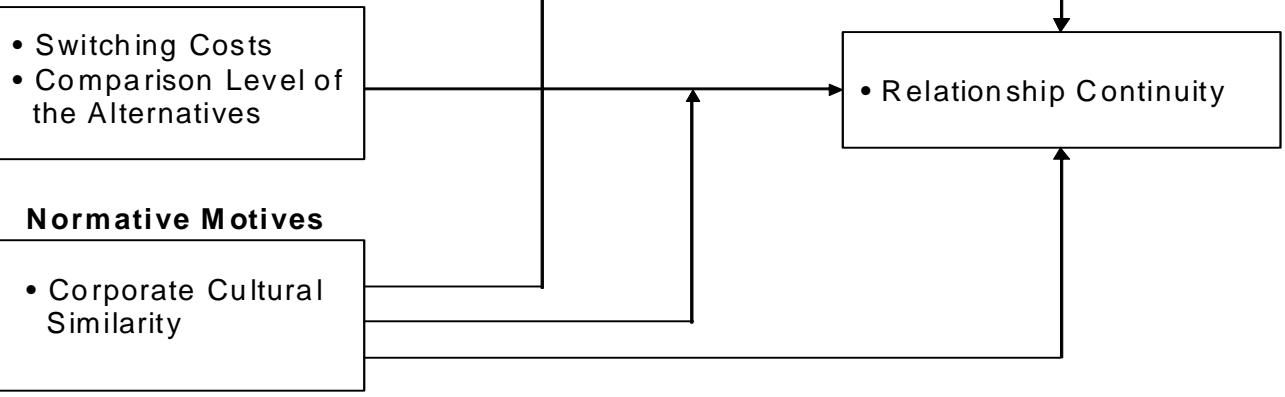

Figure 1. The proposed conceptual framework for relationship continuity

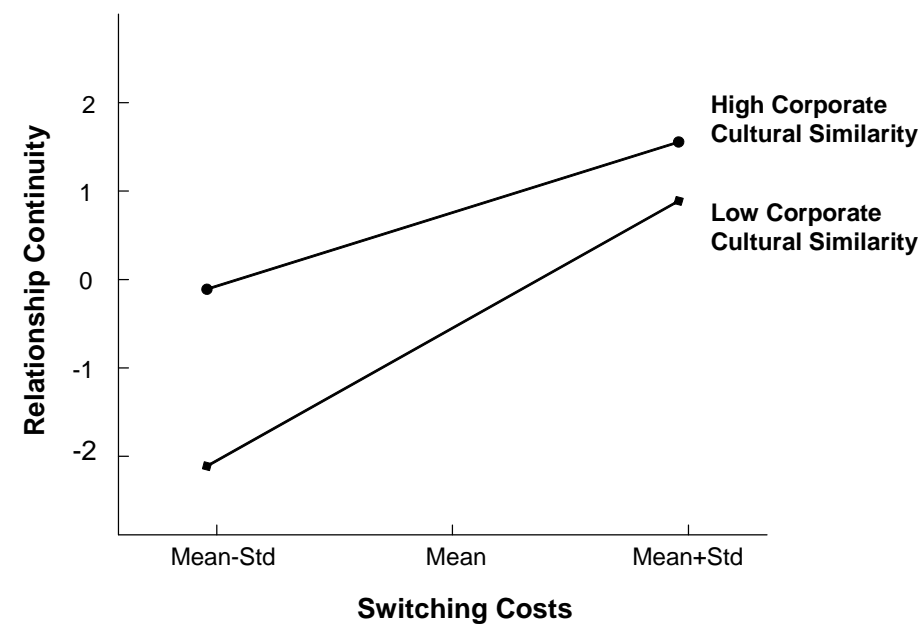

Figure 2. The moderating effect of corporate cultural similarity on the effect of switching costs on relationship continuity 